\title{
Optimization of Open Midplane Dipole Design for LHC IR Upgrade
}

R. Gupta, M. Anerella, A. Ghosh, M. Harrison, J. Schmalzle, P. Wanderer (BNL)

N. Mokhov

(FNAL)

May 16, 2005

Superconducting Magnet Division

Brookhaven National Laboratory

Operated by

Brookhaven Science Associates

Upton, NY 11973

Under Contract with the United States Department of Energy

Contract Number DE-AC02-98CH10886 


\section{DISCLAIMER}

This report was prepared as an account of work sponsored by an agency of the United States Government. Neither the United States Government nor any agency thereof, nor any of their employees, nor any of their contractors, subcontractors or their employees, makes any warranty, express or implied, or assumes any legal liability or responsibility for the accuracy, completeness, or any third party's use or the results of such use of any information, apparatus, product, or process disclosed, or represents that its use would not infringe privately owned rights. Reference herein to any specific commercial product, process, or service by trade name, trademark, manufacturer, or otherwise, does not necessary constitute or imply its endorsement, recommendation, or favoring by the United States Government or any agency thereof or its contractors or subcontractors. The views and opinions of authors expresses herein do not necessarily state to reflect those of the United States Government or any agency thereof. 


\title{
OPTIMIZATION OF OPEN MIDPLANE DIPOLE DESIGN FOR LHC IR UPGRADE*
}

\author{
R. Gupta\#, M. Anerella, A. Ghosh, M. Harrison, J. Schmalzle and P. Wanderer, BNL, NY, U.S.A. \\ N. Mokhov, FNAL, Batavia, IL, U.S.A.
}

\section{Abstract}

This paper presents the optimized designs of an "open midplane dipole" [1] for "dipole first optics" [2] for the proposed luminosity upgrade of the Large Hadron Collider (LHC). It was found [3] that in this design at luminosity of $10^{35} \mathrm{~cm}^{-2} \mathrm{~s}^{-1}$, the peak power density in the coils can be up to two orders of magnitude higher than that at the present baseline luminosity $\left(10^{34} \mathrm{~cm}^{-2} \mathrm{~s}^{-1}\right)$. This comes from a large quantity of spray particles from Interaction Point (IP) that is mostly concentrated at the midplane. The "open midplane dipole" design is the only design so far that has been found to provide reliable quench-stable operation with a lifetime of the critical components of at least ten years. In addition to a summary of magnetic, mechanical and energy deposition calculations for various iterations, the inherent benefits and challenges associated with the "open midplane dipole" design are also discussed. Results are presented for a recently proposed attractive option with the dipole splitted in two with a warm absorber placed between the two [4].

\section{INTRODUCTION}

Any upgrade in LHC luminosity or energy will require very high field magnets [5]. The proposed ten-fold increase in LHC luminosity will require high field interaction region magnets [6] that will be subjected to high radiation power. Several beam optics options are being examined involving either "quadrupole first" (current baseline) or "dipole first" layouts. "Dipole first optics" significantly reduces the long-range beam-beam effects by reducing the number of parasitic collisions by over a factor of three and makes the correction of field errors in quadrupoles more robust [6]. The radiation load is the key consideration [3] in the design of the first dipole in "dipole first optics". Energy deposition calculations show that conventional "cosine theta dipole" designs do not render a workable solution with their lifetime severely limited and cryogenic system requirements becoming prohibitive. Most of these issues are practically eliminated in an "open midplane dipole" with essentially no conductor or support structure at the midplane (see Fig. 1). The proposed "open midplane design." allows sufficient clear space between coils so that most of the particle showers from the interaction points (concentrated at the midplane due to the strong magnetic field) can be transported outside the coil region to a warm absorber.

\footnotetext{
* This manuscript has been authored by Brookhaven Science Associates, LLC under US DOE contract DE-AC02-98CH1-886. The US government retains, and the publisher, by accepting the article for publication, acknowledges, a world-wide license to publish or reproduce the published form of this manuscript, or allow others to do so, for US government purposes. "gupta@bnl.gov
}

This drastically reduces the peak power density in the coils and allows deposited energy (heat) to be removed at a higher (nitrogen) temperature where it is much more economical. The amount of heat to be removed at cold temperature is further reduced by a significant amount when the D1 dipole is split in two (D1A and D1B) with the same cross-section and a warm absorber TAS2 placed between the two [4].

The concept, however, presents several new technical challenges: (a) obtaining good field quality despite a large midplane gap, (b) minimizing peak fields on coils, (c) dealing with large vertical forces with no structure between the coils, (d) minimizing heat deposition in the cold region, (e) designing a support structure.

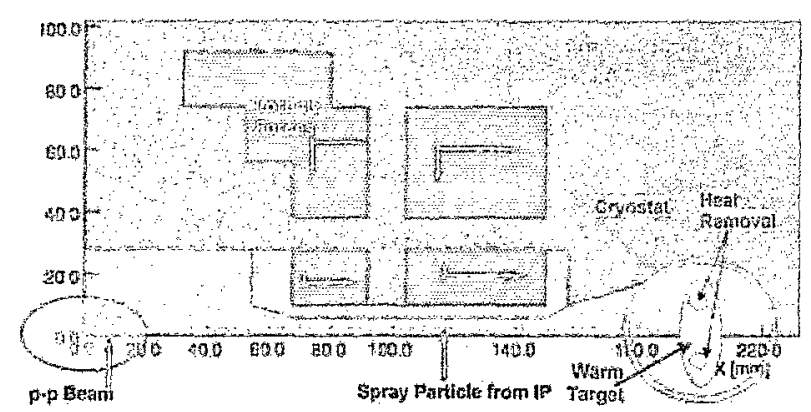

Figure 1: "Open Midplane Dipole" design that has essentially no conductor or structure at the midplane.

In most designs large vertical Lorentz forces between the upper and lower coils react against each other or would require a large support structure between the coils and midplane. A structure would, however, move the coils further away from midplane, which would in turn reduce the central field, increase the peak field and make the field quality worse. To minimize structure below lower blocks (blocks closer to midplane), we developed the magnet design such that the blocks near the midplane have net upward force rather than downward (see Fig. 1).

The proposed design is truly an "open midplane design", with no conductor or support structure between the coils at the midplane. Once the strategy of "coil design with upward force on blocks closer to midplane" is developed, any structure at midplane is counterproductive. It helps little in containing Lorentz forces but substantially increases the heat load on cold structure. It was found in earlier design studies that obstructions at midplane create a large quantity of secondary particles, which in turn deposit significant energy in superconducting coils and other cold structures and thus make the whole proposal unattractive. 


\section{DESIGN OPTIMIZATION}

To obtain a global optimization (magnet, energy deposition, beam optics), a number of magnet designs with different horizontal and vertical coil spacing and operating field were optimized. All designs offer a significant saving in the operating and infrastructure cost of the cryogenic system while providing a reliable operation where magnet will not quench due to large energy deposition and lifetime of the critical components will be at least ten years. Table 1 lists the main parameters of the various designs that were optimized during the course of this study. $\mathrm{H}$ and $\mathrm{V}$ are the horizontal and vertical coil spacing, $B_{0}$ is the design field, $B_{s s}$ is the computed short sample (quench field) for a critical current density of $J_{\mathrm{c}}$ at $12 \mathrm{~T}$ and $4.2 \mathrm{~K}, \mathrm{Cu} / \mathrm{Sc}$ is the copper to superconductor ratio in one or more blocks, $\mathrm{A}$ is the coil area (with insulation in all four quadrants), $R_{i}$ is the yoke inner radius and $R_{0}$ outer, $E$ is the stored energy, $F_{x}$ and $F_{y}$ are the horizontal and vertical forces in a quadrant of the magnet. More details of these designs can be found elsewhere [7].

Table 1: Summary of Design Iterations

\begin{tabular}{|l|c|c|c|c|c|c|}
\hline & A & B & C & D & E & F \\
\hline $\mathrm{H}(\mathrm{mm})$ & 84 & 135 & 160 & 120 & 80 & 120 \\
\hline $\mathrm{V}(\mathrm{mm})$ & 33 & 20 & 50 & 30 & 34 & 40 \\
\hline $\mathrm{V} / \mathrm{H}$ & 0.39 & 0.15 & 0.31 & 0.25 & 0.43 & 0.33 \\
\hline $\mathrm{B}_{\mathrm{o}}(\mathrm{T})$ & 13.6 & 13.6 & 13.6 & 13.6 & 15 & 13.6 \\
\hline $\mathrm{B}_{\mathrm{ss}}(\mathrm{T})$ & 15 & 15 & 15 & 14.5 & 16 & 15 \\
\hline $\mathrm{J}_{\mathrm{c}}\left(\mathrm{A} / \mathrm{mm}^{2}\right)$ & 2500 & 3000 & 3000 & 3000 & 3000 & 3000 \\
\hline $\mathrm{Cu} / \mathrm{Sc}$ & 1 & $1,1.8$ & 0.85 & 0.85 & 0.85 & 1 \\
\hline $\mathrm{A}\left(\mathrm{cm}^{2}\right)$ & 161 & 198 & 215 & 148 & 151 & 125 \\
\hline $\mathrm{R}_{\mathrm{i}}(\mathrm{mm})$ & 135 & 400 & 400 & 320 & 300 & 300 \\
\hline $\mathrm{R}_{\mathrm{o}}(\mathrm{mm})$ & 470 & 800 & 1000 & 700 & 700 & 700 \\
\hline $\mathrm{E}(\mathrm{MJ} / \mathrm{m})$ & 2.2 & 4.8 & 9.2 & 5.2 & 4.1 & 4.8 \\
\hline $\mathrm{F}_{\mathrm{c}}(\mathrm{MN} / \mathrm{m})$ & 9.6 & 10.1 & 12.3 & 9.5 & 10.4 & 9.6 \\
\hline $\mathrm{F}_{\mathrm{y}}(\mathrm{MN} / \mathrm{m})$ & -3.0 & -6.8 & -8.7 & -7.0 & -5.1 & -5.4 \\
\hline
\end{tabular}

"Design $C$ " was the most analyzed and optimized design in terms of performance, namely: good field quality (see harmonics in Table 2), support structure with deflections within prescribed limit (all relative deflections $<0.1 \mathrm{~mm}$ ) and small energy deposition on coils (see Figs. 3 and 4 and Table 3). However, the magnet became large and overly optimized (field quality and energy deposition much better than what was needed). "Design $F$ " represents a better balance (overall optimization) between cost and performance. It consists of two double-layer simple racetrack coils. The relative field errors in the region of interest (horizontal $+/-28 \mathrm{~mm}$, vertical $+/-14$ $\mathrm{mm}$ ) are kept below several parts in $10^{-3}$, as requested [8].

Table 2: Computed harmonics at a reference radius of 23 $\mathrm{mm}$ (beam size) and $36 \mathrm{~mm}$ (Max. offset) in "design C"

\begin{tabular}{|l|c|c|c|c|c|c|}
\hline & $\mathrm{b}_{3}$ & $\mathrm{~b}_{5}$ & $\mathrm{~b}_{7}$ & $\mathrm{~b}_{9}$ & $\mathrm{~b}_{11}$ & $\mathrm{~b}_{13}$ \\
\hline $\mathrm{R}=23 \mathrm{~mm}$ & 0.25 & 0.08 & 0.02 & -0.06 & 0.00 & 0.00 \\
\hline $\mathrm{R}=36 \mathrm{~mm}$ & 0.62 & 0.47 & 0.31 & -2.11 & 0.39 & 0.06 \\
\hline
\end{tabular}

\section{MECHANICAL ANALYSIS}

The design consists of two double layer racetrack coils. To maximize the open vertical space between the coils, the lower coil is contained within a machined support structure which also acts as the vacuum enclosure. The upper coil is supported by laminated collars. The collars are contained within a laminated yoke and a welded shell. A finite element analysis was done to look at the deflections due to the coil forces. Relative deflections are within $\sim 0.1 \mathrm{~mm}$ with the exception of the vertical deflection in the support web below the large upper coil block. To minimize this deflection the collar will be prebent and the coil will be pre-loaded. Stresses in the support structure are within acceptable limits. Specifying the details of the mechanical assembly and carrying out a complete mechanical analysis (2-d and 3-d) are among the remaining major tasks of this proposal.

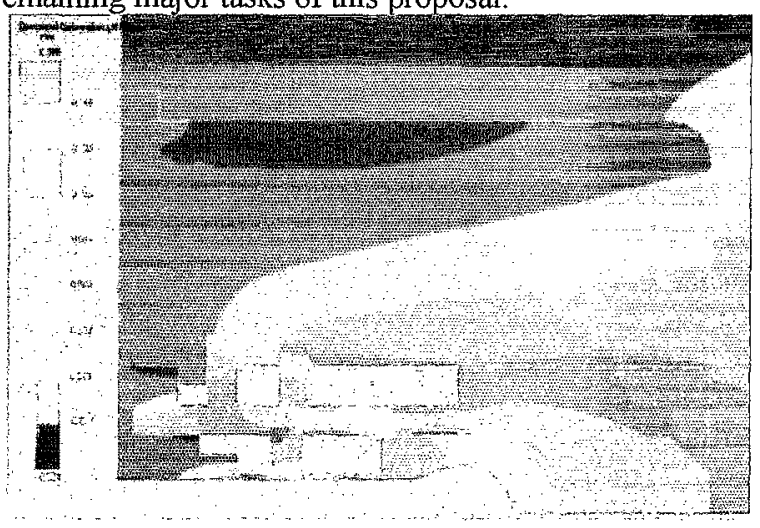

Figure 2: Horizontal deflections in "Design $\boldsymbol{F}$ " in $\mathrm{mm}$. Relative deflection are $\sim 0.1 \mathrm{~mm}$ at design field.

\section{ENERGY DEPOSITION ANALYSIS}

The radiation problems are particularly severe for the dipole-first layout, since most of the charged secondaries from the IP are swept into the D1 dipole by its high magnetic field. The open mid-plane design opens the door towards the high luminosities [3]. As a result of thorough optimization of the D1 design with iterations in mechanical and energy deposition analyses, we have arrived at the following conclusions. The front absorber TAS does an excellent protective job absorbing soft particles from the IP. Left are energetic particles swept by a strong magnetic field to the aperture, with a build-up at the D1 non-IP end. A magnetized TAS does not help; estimates show that one needs about $20 \mathrm{~T}-\mathrm{m}$ to make it working. The idea has been originated [4] to split D1 in two sections: D1A (20-T-m) and D1B and intercept particle spray from D1A by a warm absorber TAS2. This would be a natural two-stage approach to D1 design and manufacturing.

Detailed energy deposition calculations with the newest version of the MARS15 code [9] give the following configuration optimized for the 13.6-T D1 design described in the previous sections: $1.5-\mathrm{m} \mathrm{DlA}$ at $23 \mathrm{~m}$ from the IP followed by a $1.5-\mathrm{m}$ long copper or stainless steel warm absorber TAS2 with the aperture radius of 27 $\mathrm{mm}$ and $0.5-\mathrm{m}$ warm-to-cold interconnect regions on its ends, followed by a $8.5-\mathrm{m}$ long D1B. A neutral beam absorber TAN is placed at the appropriate distance downstream of D2B. Fig. 3 shows calculated energy 
deposition $R-Z$ isocontours in the optimized configuration. One sees that most of the IP beam power is deposited in the TAS, TAS2 and TAB absorbers.

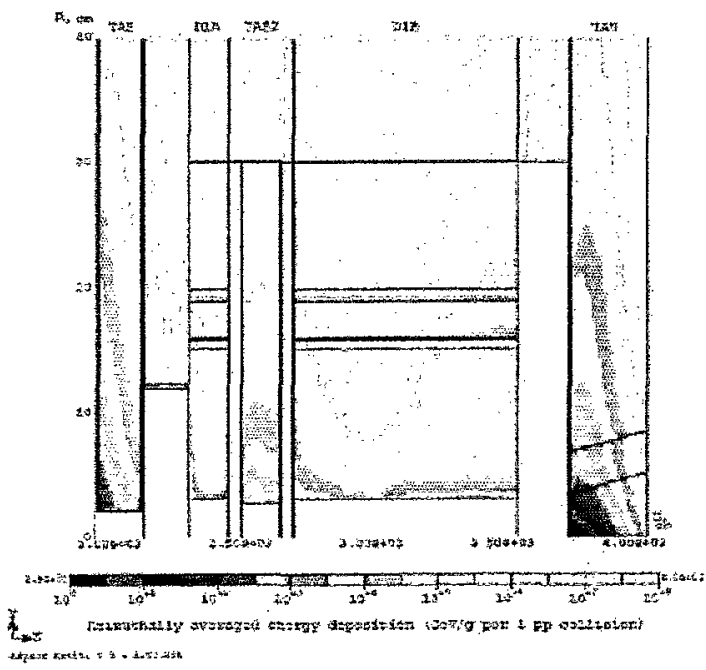

Figure 3: Azimuthally averaged energy deposition isocontours in the dipole-first IR.

A transverse profile of power density at the longitudinal maximum (non-IP end of the D1B) is shown in Fig. 4. The peak power density in the SC coils at the non-IP ends of D1A and D1B is $0.4 \mathrm{~mW} / \mathrm{g}$. This is found in the coils close to the central aperture in DIA and in the coils close to the tungsten rods in D1B. These peak values are below the estimated quench limit [3] with a necessary safety margin. The peak displacements per atom (DPA) rate is below 0.01 per year, that corresponds to a lifetime in the hottest spot of 10 years minimum. Note that these numbers for the optimized dipole-first at the luminosity of $1035 \mathrm{~cm}-2 \mathrm{~s}-1$ are very similar to the baseline quadrupolefirst design at the luminosity of $1034 \mathrm{~cm}-2 \mathrm{~s}-1$.

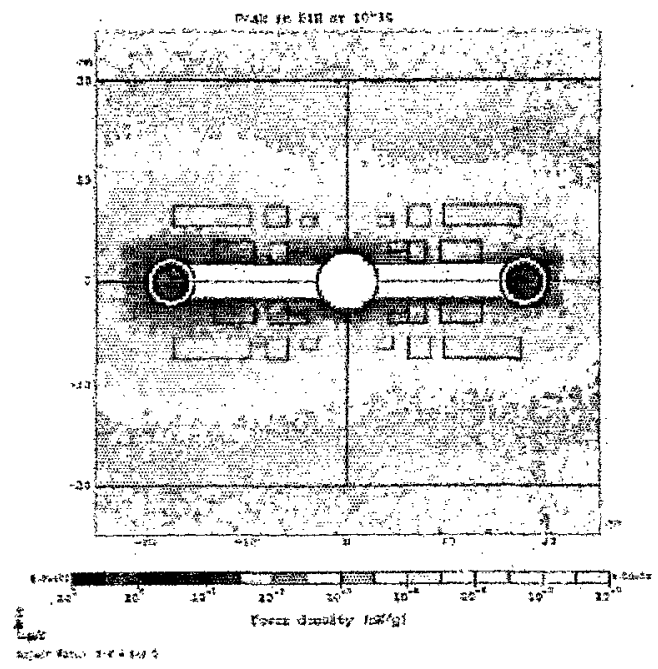

Figure 4: Power density isocontours at the non-IP end of the D1B.

The TAS2 absorbers intercepts substantial fraction of particle flow that otherwise ends up in the non-IP end of
D1. Table 3 shows distribution of the power dissipation in the system components.

Table 3: Heat loads (W) to the system components

$\begin{array}{lll}\text { D1A (1.5 m) } & & \\ & \text { Superconductor } & 3.6 \\ & \text { Collar } & 26.6 \\ & \text { Yoke } & 4.6 \\ \text { Tungsten Rod } & 1.6 \\ \text { D1B (8.5 m) } & & \\ & \text { Superconductor } & 24.1 \\ & \text { Collar } & 177.2 \\ & \text { Yoke } & 15.0 \\ & \text { Tungsten Rod } & 52.2 \\ \text { TAS } & \text { Pipes } & 7.2 \\ \text { TAS2 } & & 1830 \\ \text { TAN and Downstream } & 270 \\ \end{array}$

\section{SUMMARY}

The proposed "open midplane dipole" design allows a ten fold increase in LHC luminosity which otherwise is limited in "dipole first" optics by component lifetime, magnet quench and substantial increase in infrastructure and operating costs of cryogenic system due to excessive radiation. The design represents a significant new addition to magnet technology with challenges associated with the magnetic design, mechanical structure and energy deposition essentially met.

\section{ACKNOWLEDGMENTS}

Discussions with and feedback from S. Peggs and T. Sen on issues related to beam optics are appreciated.

\section{REFERENCES}

[1] R. Gupta, et al., "Open Midplane Dipole Design for LHC IR Upgrade," IEEE Transactions on Applied Superconductivity (MT-18), Vol. 14, No. 2 (2004), pp 259-262.

[2] O.S. Bruning et al., "LHC Iuminosity and Energy Upgrade: A Feasibility Study," LHC Project Report 626, December 2002

[3] N.V. Mokhov, et al., "Energy Deposition Limits in A Nb3Sn Separation Dipole in Front of the LHC HighLuminosity Inner Triple," PAC, Portland, USA, May 2003, http://www.jacow.org.

[4] N.V. Mokhov, "Energy Deposition in OpenMidplane Dipole", LARP Collaboration Meeting, Port Jefferson, NY, April 6-8, 2005.

[5] T. Taylor, et al., "Superconducting Magnets for a Super LHC," EPAC 2002, Paris, France, http://www.jacow.org.

[6] J. Strait, et al., "Towards a New LHC Interaction Region Design for a Luminosity Upgrade," PAC, Portland, USA, May 2003, http://www.jacow.org.

[7] http://www.bnl.gov/magnets/Staff/Gupta/

[8] M. Harrison, S. Peggs, T. Sen, "Private Communication".

[9] N.V. Mokhov, "The MARS Code System", http://www-ap.fnal.gov/MARS/. 